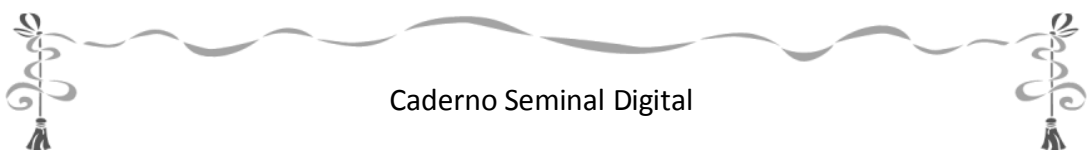

\title{
PERSPECTIVAS DE ANÁLISE SOBRE O USO DO DIMINUTIVO E DO AUMENTATIVO NA FALA BALSENSE
}

PERSPECTIVES OF ANALYSIS ON THE USE OF DIMINUTIVE AND AUGMENTATIVE FORMS IN THE BALSENSE SPEAK

\author{
Gisélia Brito dos Santos \\ UEMA/UFG \\ Marcia Meurer Sandri \\ UEMA/UERJ
}

Resumo: Este trabalho traz uma análise das ocorrências do diminutivo e do aumentativo na fala do sertanejo do Sul do Maranhão. Apresenta-se a formação do diminutivo e do aumentativo e a conotação emocional e cognitiva que envolve a sua produção, assim como a quantificação dos usos em relação ao gênero do falante.

Palavras-chave: Aumentativo. Diminutivo. Sertanejo. Região de Balsas-MA. Abstract: This paper presents an analysis of the occurrences of the diminutive and augmentative in the speech in the backcountry of Southern Maranhão. We present the formation of the diminutive and augmentative and the connotations they have, approaching the cognitive and emotional issues surrounding this production, as well as the quantification of uses in relation to the gender of the speaker.

Keywords: Augmentative. Diminutive. Backcountry. Region of Balsas-MA.

\section{INTRODUÇÃO}

Ao realizarmos a análise dos aspectos do diminutivo e do aumentativo na fala do sertanejo do Sul do Maranhão, categorizamos gramaticalmente as palavras que apresentam o grau (aumentativo e diminutivo) e apreciamos o contexto em que elas são empregadas. Fazemos uma categorização da

Caderno Seminal Digital Ano 19, no 19, V. 19 (Jan-Jun/2013) - ISSN 1806-9142
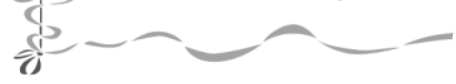

209

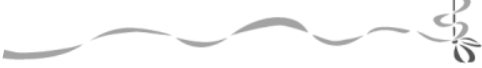


ocorrência e da maior recorrência desse processo no que se refere ao gênero do falante (colaborador), extraídos do corpus da dissertação de mestrado, "Descrição histórica das vogais na fala do sertanejo da região de Balsas-MA", de Castro (2008). Extraímos as ocorrências de diminutivo e aumentativo da fala de duas mulheres e de cinco homens que têm acima de 50 anos, são moradores da zona rural da região de Balsas. Os dados foram gravados em $\mathrm{mp3}$.

Para realizar essa análise tivemos como base a leitura de alguns estudiosos que convergem e outros que divergem no que se refere à taxionomia usada para classificar o processo de formação de grau dos nomes, se flexão, se derivação ou se processo independente na gramática. Dixon e Aikhenvald (2007), Bechara (2001), Araújo (1985) e Câmara Jr. (1970) classificam a formação do aumentativo e do diminutivo como derivação, Almeida (1994) apresenta o grau como flexão, e Lee (1999) aborda a formação do grau como um estatuto independente na gramática. Bechara (2001) e Araújo (1985) tratam ainda da produtividade do uso do grau no português brasileiro e da conotação sentimental e afetiva que envolve o emprego desse recurso gramatical da língua.

A categorização das ocorrências na fala dos informantes é feita de acordo com a classe gramatical a que pertence a palavra. As ocorrências são observadas em substantivos (próprio e comum), adjetivos e advérbios. Em seguida, procedemos à análise quantitativa das mesmas,

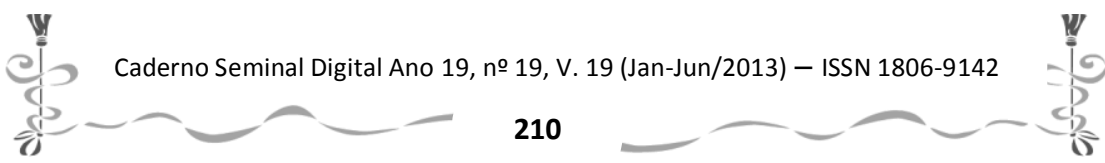


Caderno Seminal Digital

î.

mostrando o número de ocorrências de grau, tendo como parâmetro a classe gramatical das palavras e o gênero do falante.

As palavras utilizadas na análise, retiradas do corpus já mencionado, serão transcritas com reprodução da pronúncia e do padrão ortográfico.

\section{A PALAVRA E SUAS FACES}

Cada uma tem mil faces secretas sob a face neutra e te pergunta, sem interesse pela resposta, pobre ou terrível, que lhe deres: Trouxeste a chave? (Carlos Drummond de Andrade)

A palavra e sua definição têm gerado muita polêmica. Os estudos linguísticos têm a palavra como "unidade básica da língua" (DIXON; AIKHENVALD, 2007). Para Lyons (1977), ela é a unidade linguística da gramática normativa. Bolinger ${ }^{36}$ (1963) define a palavra como "fonte de contrastes fonêmicos". Bloomfield (1979) conceitua a palavra como forma livre mínima. Esses e outros conceitos em torno da palavra não são suficientes para defini-la, apenas oferecem pistas do que ela possa ser ou representar.

Dixon e Aikhenvald (2007) apresentam alguns critérios para definição da palavra, mostrando a visão de vários autores, do ponto de vista fonológico, gramatical e

\footnotetext{
${ }^{36}$ A referida definição de Bolinger, por não ter sido encontrada, foi retirada da obra de DIXON, R. M. W.; AIKHENVALD, A. Y. Word A Cross-Linguistic Topology.

Cambridge: Cambridge University Press, 2007.
}

Caderno Seminal Digital Ano 19, no 19, V. 19 (Jan-Jun/2013) - ISSN 1806-9142

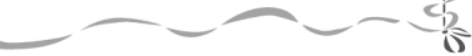


ortográfico. Para eles, a palavra fonológica é uma unidade da fonologia que excede os limites da sílaba e tem propriedades que são organizadas a partir de regras, traços segmentais e prosódicos; a palavra gramatical consiste num número de elementos gramaticais que ocorrem juntos, em ordem fixa, com ocorrência e significado convencionados; a palavra ortográfica é um agrupamento de morfemas organizados e separados entre espaços em branco.

Diante dessas definições de palavra podemos considerá-la como elemento fundamental numa língua e nos estudos linguísticos. A palavra contém carga semântica lexical e constitui os componentes do universo empírico e linguístico. Ela, em si mesma, é a base para a formação de novas palavras e para a comunicação. Na palavra são aplicados os processos gramaticais, fonológicos e morfológicos de uma língua. É a palavra que o falante usa, transforma e modifica, através dos processos de derivação, composição e flexão de uma língua. No processo de formação e flexão das palavras, o falante se utiliza de sua criatividade e de seu conhecimento científico ou empírico, para fazer com que existam variedades em uma língua. Nesse aspecto, a palavra se torna objeto de uso cotidiano, instrumento representador de um povo, de uma cultura, de um jeito particular de viver.

O processo de formação das palavras envolve a composição, que é a junção de duas ou mais palavras gramaticais as quais formam uma palavra fonológica; a

Caderno Seminal Digital Ano 19, no 19, V. 19 (Jan-Jun/2013) - ISSN 1806-9142 
â.

derivação, que cria um novo vocábulo com o acréscimo de afixos, ou com a mudança de significado de uma palavra já existente na língua. Há também a formação de palavras por meio de siglas, abreviaturas e outros processos. Dixon e Aikhenvald (2007) afirmam que a derivação é característica das línguas sintéticas e a difere da flexão, e a morfologia derivacional cria novas palavras, com novos significados. A flexão, por sua vez, abarca a especificidade gramatical pertencente a uma classe de palavras particular. Esta acrescenta a uma palavra já existente desinências nominais e desinências verbais.

Câmara Jr. (1970) apresenta a formação do grau como um fator derivacional e demonstra com os diminutivos. A derivação envolve as classes abertas, como substantivo, adjetivo e advérbios (DIXON; AIKHENVALD, 2007). Tanto Dixon e Aikhenvald como Câmara Jr. dizem que as categorias tipicamente derivacionais são as que envolvem a formação do diminutivo e do aumentativo.

Apesar de envolverem, principalmente, as palavras do inventário aberto da língua (MACAMBIRA, 1999), os recursos derivacionais, algumas vezes, são aplicados às palavras do inventário fechado, como é o caso da formação do diminutivo a partir de demonstrativos no português brasileiro, como demonstram Dixon e Aikhenvald (2007), com os exemplos esse-zinho, aquele-zinho. Estes usados na variedade coloquial

Caderno Seminal Digital Ano 19, no 19, V. 19 (Jan-Jun/2013) - ISSN 1806-9142 
Caderno Seminal Digital

î.

do português do Brasil de forma pejorativa ou com uma conotação de menosprezo.

\section{A FORMAÇÃO DO DIMINUTIVO E DO AUMENTATIVO NO PORTUGUÊS BRASILEIRO}

\subsection{Algumas abordagens teóricas}

As gramáticas tradicionais, entre elas a Gramática Metódica da Língua Portuguesa de Almeida (1994), definem o processo de formação do diminutivo e do aumentativo, no português, como flexão, assim como a formação de gênero e de número e a conjugação dos verbos. Muitos estudos acerca do grau dos nomes têm sido feitos por pesquisadores que já não têm mais na gramática tradicional a fonte de seus pressupostos teóricos. Entre estes estão J. M. Câmara Jr. (1970), Seung-Hwa Lee (1999), G. M. L. de Araújo (1987), R. M. W. Dixon e A. Y. Aikhenvald (2007), E. Bechara (2001), entre outros.

Esta nova perspectiva de estudo, especificamente dos processos de formação e flexão de palavras, na língua portuguesa, teve início com o desenvolvimento dos estudos linguísticos no Brasil, quando os fenômenos da língua começaram a ter uma nova interpretação e as lacunas deixadas pela gramática normativa foram sendo preenchidas. Araújo (1985) atesta que as palavras formadas a partir da derivação possuem o mesmo "status gramatical, paradigmas flexionais e funções sintáticas" que têm as palavras das quais

Caderno Seminal Digital Ano 19, no 19, V. 19 (Jan-Jun/2013) - ISSN 1806-9142
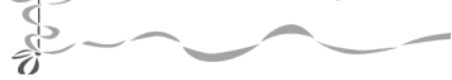

214

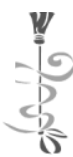


elas derivam. Ela defende a derivação como formadora de novas palavras porque esse processo é optativo e não sistemático, pois, por questões de estilística e de gosto do falante, ele pode usar muito simpático por simpaticíssimo, muito magro por magérrimo e assim por diante. Com base nestas evidências, Araújo (1985) sugere a derivação e a composição como componentes de um mesmo fenômeno gramatical.

Portanto, a formação do diminutivo e do aumentativo em vez de flexão de grau passa a ser considerada derivação que com o acréscimo de -inho ou -zinho e -ão ou -zão, na maioria dos casos, forma novas palavras a partir de um nome já existente. Câmara Jr. (1970) apresenta a categorização de grau como derivação e acrescenta que categorizá-la como flexão não passa de uma inclusão errada de um aspecto da gramática latina para a gramática portuguesa, justamente por a flexão latina constituir-se pela declinação, o que não ocorre em português. Isto se reforça quando observamos que o diminutivo abarca advérbios, e estes não são membros das classes de palavras que normalmente recebem a flexão, como os nomes e os verbos. O autor diz ainda que o uso do grau, considerado como um processo de derivação, é muito particular e pessoal, não é obrigatório, pois o falante o escolhe ou não. "Não é um mecanismo obrigatório e coerente, e não estabelece paradigmas exaustivos e de termos exclusivos entre si" $(1979$, p. 83).

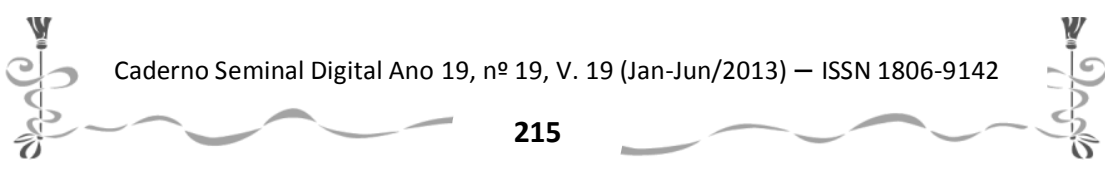


Nessa mesma linha de pensamento, Bechara (2001) apresenta esse processo como componente da derivação e mostra uma lista de sufixos formadores do diminutivo e do aumentativo. Este autor defende que a formação de grau dos nomes, na língua portuguesa, se dá por mecanismos derivacionais ou sintáticos e confirma isso dizendo que a derivação gradativa dos substantivos ocorre de duas maneiras, uma sintética e outra analítica. A primeira abarca a formação do diminutivo e do aumentativo com os diversos alomorfes ${ }^{37}$ formadores desta categoria. A segunda é realizada com a adição de uma palavra que indica diminuição ou aumento, como grande ou pequeno(a), por exemplo. Tal fato, para este autor, tira esta produtividade do nível flexional, pois a flexão ocorre de maneira sistemática, coerente e obrigatória, o que não se processa na derivação.

Uma abordagem um pouco diferente é feita por Lee (1999). Ele afirma que a formação do diminutivo no português brasileiro é muito produtiva com os sufixos -inho e -zinho. Lee (1999) classifica este processo de duas maneiras com base no

${ }^{37}$ Para Câmara (1970) -inho e -zinho são, respectivamente, morfema e alomorfe formadores de diminutivo. $\mathrm{O}$ alomorfe tem distribuição complementar para atender a formações junto a bases atemáticas. Vejamos: o diminutivo e o aumentativo de menino se realiza com -inho e -ão, respectivamente; enquanto para amor, usam-se -zinho e -zão.

Caderno Seminal Digital Ano 19, no 19, V. 19 (Jan-Jun/2013) - ISSN 1806-9142 
uso do sufixo. Se o diminutivo é formado com -inho, ele é um processo de derivação, isto porque este morfema é um sufixo. Se formado com -zinho é considerado composição pós-lexical, pois este afixo é visto como um elemento formador de um composto, uma palavra prosódica. Mas o autor continua dizendo que, em relação a esta taxionomia, há alguns problemas:

1) -inho: não se submete à regra de neutralização vocálica como acontece nos derivados, não se aplicam regras de alomorfia (assimilação e abrandamento da velar), não define gênero, como os sufixos derivacionais. Com isso, a produtividade, com esse sufixo, não pode ocorrer no nível da derivação.

2) -zinho: apresenta transposição de acento, submete-se à lei de preservação da estrutura, ao contrário dos compostos pós-lexicais. Por isto, esta formação não pode ser classificada no nível da composição.

Tiradas estas possibilidades, o autor diz que esta formação com os dois diminutivos encaixa-se no nível flexional, uma vez que as propriedades morfológicas são iguais às de flexão e as vogais médias envolvidas no processo não sofrem neutralização vocálica. Após analisar algumas regras de domínio morfológico e prosódico, Lee (ibidem) conclui que a realização do diminutivo no português brasileiro não se enquadra no nível da derivação, da flexão ou da composição e

Caderno Seminal Digital Ano 19, no 19, V. 19 (Jan-Jun/2013) - ISSN 1806-9142
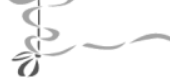
Caderno Seminal Digital

a

afirma que ela deve ser considerada um "estatuto independente na gramática" (1999, p.122).

Aikhenvald (2007) diz que a produtividade do diminutivo no Português do Brasil é mais frequente com alguns sufixos como -inho(a) e -zinho(a) e não muito com o sufixo emprestado do Tupinambá -mirim, e o sufixo -eco. O mesmo acontece com os formadores de aumentativo -(z)ão e -(z)ona que são mais produtivos, ao passo que o sufixo -aço(a) não o é. A autora justifica esta não produtividade, ou produtividade restrita, por meio de fatores fonológicos, morfológicos, semântico-pragmáticos e lexicais. Em relação aos fatores semânticos, é sabido que alguns usos do diminutivo e do aumentativo têm uma conotação pejorativa, o que lhes limita a produtividade, como é o caso de bonzinho (bobo, inocente), comidinha (comida que não é boa), sapatão (lésbica). O mesmo diz Bechara (2001, p.141) quando menciona que alguns sufixos de aumentativo e diminutivo, além de indicarem tamanho - grande e pequeno são usados de forma pejorativa ou afetiva, são os chamados "aumentativos e diminutivos afetivos", que expressam: i) crítica, desprezo, ironia, com base na conotação semântica do nome, e com o auxílio da entonação que pode ser de admiração, euforia, lamentação, ironia; ii) carinho, afetividade, amparados pela ideia de pequenez, como no caso de mãezinha, amorzinho, filhinho. 0 autor afirma ainda que o diminutivo com estes dois sufixos assume conotação patronímica quando o nome dos pais e filhos é o mesmo,

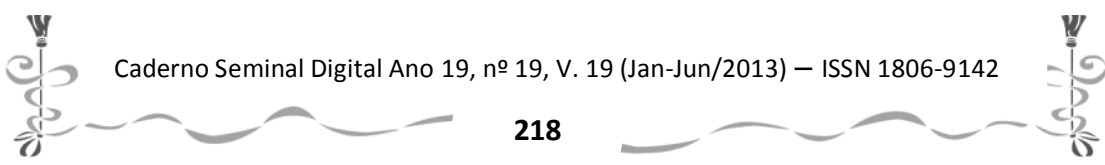


Caderno Seminal Digital

位

como vemos em Pedro (pai), Pedrinho (filho), Ana (mãe), Aninha (filha).

\subsection{Análise dos dados}

O uso do diminutivo e do aumentativo, por ser optativo e estilístico, envolve questões emocionais. 0 emprego do diminutivo envolve o sentimento, a afetividade do falante, que assim torna a expressão um pouco mais agradável. É isto que faz o sertanejo da região de Balsas ao falar das coisas do seu cotidiano, tais como rossĩa, pexim, gatim, gadim, algudãuzim, ao qualificar o mundo que o rodeia bonzim, piquininim, coitadim, poquim, fraquim. "É o uso do diminutivo conotando não a dimensão da coisa ou do ser, mas a carga afetiva em jogo (que como os efeitos rítmicos que adquirem ou desencadeiam) faz da língua portuguesa uma língua bela e agradável" (ARAÚJO, 1985, p. 59). É o que podemos ver no uso dos sufixos de aumentativo (-ão e -ona) e diminutivo (-inho e -zinho) - este com um maior número de ocorrências - nos substantivos, adjetivos e advérbios, na fala dos sete sujeitos entrevistados, os quais estão sendo trabalhados neste artigo.

Observamos, ainda, que o emprego da graduação abarca também nomes próprios de rios, Bausĩa, e de lugares, Veredãum. Nos dados que apresentamos a seguir, os números entre parênteses referem-se à quantidade de ocorrências de uma mesma palavra e os determinantes que antecedem o

Caderno Seminal Digital Ano 19, no 19, V. 19 (Jan-Jun/2013) - ISSN 1806-9142
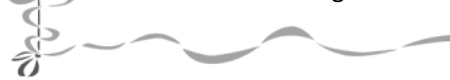

219

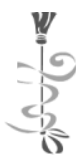


nome indicam a substantivação do adjetivo ou do advérbio. A referência aos sujeitos falantes será feita pela numeração que os antecede. Vejamos as ocorrências.

\section{1) Informante I}

Na fala desse informante há ocorrência de diminutivo em nove substantivos, dos quais seis são comuns - dierim, pexim, alfinim, gatim, copim, rossĩa - e três são próprios Manezim, Anĩa, Ritĩa - e ainda, em três adjetivos coitadim, vermelim, alvim - . Nessa entrevista, a pesquisadora usa três palavras no diminutivo, sendo que duas são substantivos próprios - Maneuzim (2) e uma comum gadim. Nesta fala não há registros de palavras no aumentativo.

\section{2) Informante II}

Esse informante apresenta em sua fala oito palavras no diminutivo e uma no aumentativo. O processo é feito em seis substantivos comuns - pezim, algudãuzim (2), cartauzim, burrim, salzim, um adjetivo - piquininim - e um advérbio eu entru bonzim... Nessa entrevista não há registros de diminutivo e de aumentativo na fala da pesquisadora. Foi registrado o emprego de aumentativo em um adjetivo grandãum - na fala de uma das colaboradoras.

\section{3) Informante III}

$\mathrm{Na}$ fala dessa informante há ocorrência de sete palavras no diminutivo e não há nenhum registro de

Caderno Seminal Digital Ano 19, no 19, V. 19 (Jan-Jun/2013) - ISSN 1806-9142 
aumentativo. O diminutivo está em quatro substantivos comuns (historĩa, aguĩa (2), diẽrim), em um adjetivo (suadĩa) e em dois advérbios - pertim e direitim.

\section{4) Informante IV}

Na fala desse informante há ocorrência de trinta e duas palavras no diminutivo, dentre elas, dezenove são substantivos comuns - vidĩa (2), carrim, dierim, radim, partim (2), bracim, solim, restim (2), tiquizim (2), bichim, eguĩa, gadim, mijolim, porquim, caldim -, duas são substantivos próprios - Bausĩa, Paulim -, quatro são adjetivos - agasaiadim, baratim, poquim e brigadim - e quatro são advérbios - ligerim, baratim e divagazim (2). Ressaltamos o fato de a palavra brigadim ter uso interjectivo, ou seja, ocorre também como agradecimento, como interjeição adjetiva brigadim. Não há registros de nomes no aumentativo.

\section{5) Informante $V$}

Esse informante faz uso de treze palavras no diminutivo, sendo que cinco são substantivos comuns quadrim, coisĩas, (um) poquim, brejim e sonim -, cinco próprios - Raimundim (2), Bal(i)sĩa (3) -, há duas ocorrências do adjetivo poquim (2) e o advérbio jeitim. Nesta fala há registros de uma palavra no grau aumentativo, o substantivo próprio Zezãum.

Caderno Seminal Digital Ano 19, no 19, V. 19 (Jan-Jun/2013) - ISSN 1806-9142 


\section{6) Informante VI}

Essa informante faz uso de seis diminutivos em substantivos comuns - (um) poquim (2), pinguim, aguĩa, saquim, bichĩa - e um em adjetivo (fraquim). Há o emprego de duas palavras no aumentativo, as duas são substantivos comuns (assautãum, roçona).

\section{7) Informante VII}

Esse informante faz uso de dezoito palavras no diminutivo e uma no aumentativo. Das que estão no grau diminutivo, duas foram usadas pela pesquisadora: uma é substantivo próprio - Bausĩa - e a outra é substantivo comum - cafezim - Das usadas pelo entrevistado, doze são substantivos comuns - gadim (3), pedacim, carrêrim (2), casĩa, impreguim, fazendĩa (2) e cafezim (2) -, dois adjetivos - istreitĩa e caladim - e dois advérbios - sozim e pertim -.

O entrevistado usou uma palavra no aumentativo que é um substantivo próprio - Veredãum - que designa um local na zona rural pesquisada.

\subsubsection{Análise morfofonológica}

Os sufixos utilizados na graduação foram somente inho e -zinho para o diminutivo e -ão e -zão para o aumentativo. Com base nos postulados de Lee (1999), -inho é afixado, de modo geral, às formas não verbais que têm

Caderno Seminal Digital Ano 19, no 19, V. 19 (Jan-Jun/2013) - ISSN 1806-9142 
Caderno Seminal Digital

id

marcadores de palavra ${ }^{38}$ e -zinho às formas não verbais sem marcadores de palavras, às palavras terminadas em sílabas pesadas (sílabas que terminam em consoante e/ou semivogal, como: pas-ta, car-go, pau-ta, pai) e às que são proparoxítonas. Nos discursos analisados não há presença de proparoxítonas no diminutivo e há o emprego desta afixação em todos os vocábulos com sílabas pesadas. São eles: algodão $>$ algodãozinho > algudauzim, cartão > cartãozinho > cartauzim, bom > bonzinho > bonzim, manoel > manoelzinho $>$ manelzim, sal > salzinho > salzim, devagar > devagarzinho > devagazim, só > sozinho > sozim, pé > pezinho > pezim. A forma sem marcador de palavra que faz a graduação em zinho é uma paroxítona: parte > partizinha.

Os registros de -inho(a) são feitos em formas com marcadores de palavras paroxítonas e ficam com o morfema de diminutivo reduzido em -im ou -ĩa, como em: agasalhado > agasalhadinho > agasaiadim, água > aguinha > aguĩa, alvo > alvinho > alvim, ana > aninha > anĩa, bicho > bichinho > bichim, bicha> bichinha > bichĩa, égua > eguinha > eguĩa, história > historinha > historĩa, sol(soli) > solinho > solim, peixe $>$ peixinho > peixim. A palavra sol, usada pelo falante 4 , foi analisada como paroxítona, pois o informante emprega a variação soli. Desta forma, de oxítona com sílaba pesada, ela passa a paroxítona, fazendo o diminutivo em -inho e não em -

${ }^{38}$ Palavras que não possuem a desinência indicadora de gênero, tais como: parte, sol, caju, saci.

Caderno Seminal Digital Ano 19, no 19, V. 19 (Jan-Jun/2013) - ISSN 1806-9142 
Caderno Seminal Digital

zinho como seria a regra para as palavras que terminam com sílaba pesada.

Ainda segundo Lee (1999), o acréscimo dos sufixos do diminutivo não muda a palavra que os recebe nos aspectos lexicais e no gênero, o que comprovamos com os exemplos: $o$ café < o cafezim, a vida < a vidĩa, um bicho < um bichim .

O fenômeno de redução dos dois morfemas de grau produtivos na fala do sertanejo estudado, ocorrido nos substantivos, adjetivos e advérbios, sofreu um fenômeno de redução chamado truncamento. Segundo Araújo G. (2002), truncamento é uma abreviação ou encurtamento de uma palavra-matriz, sem a perda do valor semântico. Os encurtamentos observados foram registrados nas palavras com os morfemas de diminutivo -inho(a) e -zinho, que se reduzem em -im, -ĩa e -zim respectivamente, como vemos em gadim < gadinho, cafezim < cafezinho, aguĩa < aguĩa, fazendĩa $<$ fazendinha. As palavras com sufixo de aumentativo preservam a forma padrão do aumentativo em -ão e -ona. Com o -ao, ocorre a harmonia silábica com a dissimilação do $o$ final em $u$ e com o espraiamento da nasalidade, como observamos em grandãum < grandão, veredãum < veredão, asfautaum < asfalto. A forma em -ona não sofre alterações, roçona. As palavras com os sufixos do diminutivo que não sofreram truncamento foram usadas pela pesquisadora, são elas: poquinhu, riachinhu, em 2, coisinha, partizinha em 5 e direitinhu em 6 . Ocorre nestas palavras apenas a harmonia

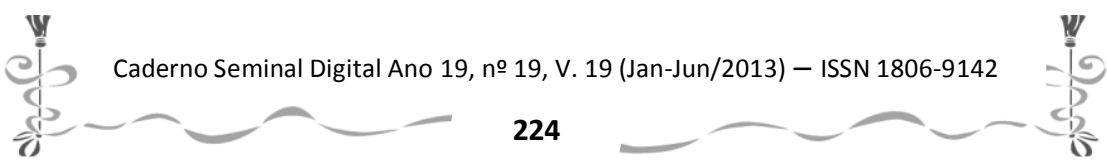


Caderno Seminal Digital

行

silábica com a dissimilação do $o$ em $u$ nas palavras masculinas e nenhuma mudança nas femininas.

Há uma flutuação de classe gramatical das palavras de acordo com o contexto nas quais são usadas. Vejamos algumas ocorrências:

3) A palavra pouco, segundo o Dicionário Houaiss (2001), pode ser um pronome, um advérbio, ou, um substantivo. No corpus analisado, de acordo com a estrutura sintática do enunciado, ela aparece em duas categorias gramaticais: i) substantivo: substantivadas pela presença do determinante "até mais um poquim" em 5, "cada quein comprava um poquim" e "Só um poquin mermu" em 6; ii) adjetivo: qualificando o substantivo presente no sujeito da oração "Mas já é tãu poquinhu" em 3, "marr'é poquim" em 4, "É córregu quandu é poquim", em 5 . Não observamos registros desta palavra como pronome ou advérbio.

4) As palavras bom em 2 "eu entru bonzim" e ligeiro em 4 "i si acaba ligêrim" que, conforme o dicionário são adjetivos, nos discursos analisados estão adverbializadas, acrescentando circunstâncias de modo aos verbos entrar e acabar.

5) Direito, barato e só podem ser categorizadas como adjetivos ou advérbios conforme o ambiente sintático no qual elas são empregadas. Nos discursos analisados, direito em 3 "Marcu mĩa consuta direitinhu", acrescenta uma circunstância de modo ao verbo marcar, portanto é advérbio; barato em 4 é

Caderno Seminal Digital Ano 19, no 19, V. 19 (Jan-Jun/2013) - ISSN 1806-9142

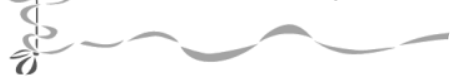

225

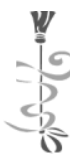


usado como adjetivo, caracterizando o substantivo "Aí já num é baratim" e como advérbio, acrescentando circunstância ao verbo deixar "qui dexei baratim";

A palavra jeito, substantivo, conforme o dicionário Houaiss (2001), assume função de advérbio, em 5 , quando se refere ao verbo fazer, como vemos na locução adverbial "faiz ... du jeitim qui é ali".

\subsubsection{Análise semântico-pragmática (cognitiva)}

Todos os diminutivos estudados neste artigo envolvem o sentimento do falante ao nomearem as coisas de seu universo particular, como fazenda, gado, roça, feijão, vida, o rio que passa na localidade, os nomes dos lugares, as pessoas próximas, enfim, tudo que rodeia a vida do sertanejo, neste caso, da região de Balsas. A entrevistadora também faz uso das mesmas palavras, ou de palavras diferentes, no grau aumentativo e diminutivo. Isto acontece porque ela usa uma técnica de pesquisa de campo que é a adequação do vocabulário e do jeito de falar à realidade do sujeito pesquisado.

O diminutivo e o aumentativo, como mostra Bechara (2001), além de tamanho - pequeno e grande - podem ter conotação pejorativa, conforme o significado do item lexical usado; e afetiva, principalmente se relacionados a pessoas e coisas ligadas emocionalmente a quem fala.

Caderno Seminal Digital Ano 19, no 19, V. 19 (Jan-Jun/2013) - ISSN 1806-9142
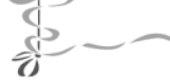
No corpus analisado não se percebeu a conotação pejorativa que pode ser expressa na graduação, pois na fala não houve situações que exigissem ou demonstrassem esse cunho pejorativo.

Em relação ao uso afetivo, este foi percebido em grande número, pois o informante fala das coisas de sua vida, de seu dia a dia, das pessoas com as quais convive, admira ou mesmo de alguém que prestou algum tipo de ajuda ou serviço relevante ao falante ou à família dele. Este emprego é percebido em gatim, rossĩa, coitadim e gadim em 1; burrim, piquininim e bonzim em 2; historĩa, pertim, direitim e riachim em 3; carrim, bracim, radim, mijolim e Bausĩa em 4; quadrim, brejim, sonim e jeitim em 5; saquim, fraquim, bichĩa e direitinhu em 6; cafezim, gadim, fazendĩa e casĩa em 7. Observou-se que o falante 5 ao usar bichĩa expressa, além de carinho, um tratamento respeitoso, ao falar com a entrevistadora. É comum, nesta região, o uso de termos como fiĩa (filha), bichĩa, cumadĩa (comadre), tanto por mulheres como por homens, ao falarem com alguém que conhecem bem, que têm parentesco, que têm relações de amizade ou mesmo alguém que não conhecem, mas que por elas têm respeito e/ou admiração, no caso aqui da entrevistadora. 0 uso carinhoso destes termos de tratamento no diminutivo aproxima locutor e interlocutor e só ocorre quando realmente a relação entre eles não tem barreiras ou está confiante e agradável.

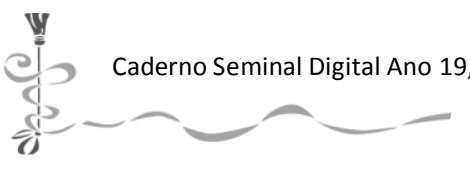


Bechara (ibidem) afirma também que os usos dos diminutivos podem ter conotação patronímica, quando pais e filhos têm o mesmo nome, como citado anteriormente. Foi possível perceber nas falas analisadas alguns usos de nomes próprios de pessoas e lugares no diminutivo e aumentativo. Os nomes de pessoas usados no diminutivo podem expressar conotação patronímica, como Ritĩa, Anĩa e Manezim em 1; Paulim em 4; e Raimundim em 5; estes nomes podem indicar a filiação, mas neste caso, eles conotam admiração, respeito e gratidão às pessoas donas dos nomes, pois estes sentimentos são características do sertanejo da região estudada. Para eles, esse tratamento é expressão de honestidade, respeito e consideração pelo outro. O nome próprio de pessoa utilizado no aumentativo, Zezaum, em 5 expressa tamanho, pois a pessoa é de estatura alta e forte. Além disso, mostra poder, autoridade. Este é um sujeito que possui riquezas e poder na região. Com isso, percebe-se que há uma relação semânticocognitiva com a formação do diminutivo e do aumentativo neste falar. Isto também é demonstrado no uso da palavra Veredãum em 7, nome de lugar que deriva do nome de planta chamada Vereda. Esta é uma planta medicinal, forte, amarga que serve para problemas no fígado, no estômago e dela se extrai substância empregada na curtição de cachaça. É muito usada na região. A denominação do lugar indica força, bravura; que este lugar é fértil para este vegetal e tem grande quantidade dele.

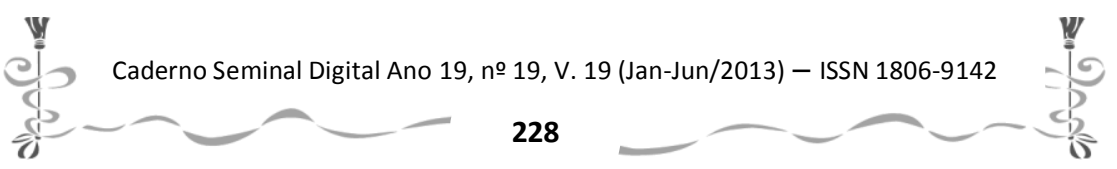


Em relação aos diminutivos usados em algumas palavras que mostram riqueza material ou poder do dono proprietário (sujeito nomeado), há aqui uma certa modéstia, própria do sujeito falante em relação aos bens materiais, com a intenção de não demonstrar que tem mais do que o necessário para viver; revela com isso simplicidade e humildade no modo de viver. Observamos isso nas palavras dierim, rossĩa e gadim em 1; poquinhu em 2; dierim em 3; dierim, gadim, poquim, tiquinzim em 4; poquim em 5; poquim, saquim e pinguim em 6; gadim, pedacim, casĩa e fazendĩa em 7.

Há a ocorrência de Bausĩa na fala de vários informantes, este nome denomina um rio que corta a região dos Gerais de Balsas. No município, há ainda o rio maior que dá nome ao município, Balsas. $O$ emprego do diminutivo na formação do nome do rio indica tamanho, o Rio Bausĩa é menor que o Rio Balsas, é como se fosse filho dele. Aqui, além da noção de tamanho, há, num sentido conotativo, uma relação patronímica no uso do diminutivo.

\section{CONSIDERAÇÕES FINAIS}

A partir da análise dos dados, optamos por não categorizar o diminutivo e o aumentativo como o fazem os autores citados neste trabalho, pois para isso é necessário uma pesquisa maior e mais aprofundada a respeito. Mas, podemos dizer que este é um processo muito produtivo no

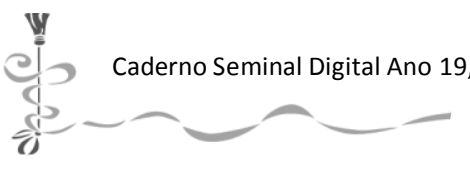

229 
falar do sertanejo da região pesquisada e que envolve questões tanto gramaticais como cognitivas.

O que emerge dos dados é que os sufixos de diminutivo mais produtivos no falar da região de Balsas são inho e -zinho, os quais em sua maioria sofrem redução em -im ou -ĩo(a) e -zim, processo que chamamos, com base nos trabalhos de Araújo G. (2002), de truncamento. Os afixos que não sofreram redução estão em algumas palavras utilizadas pela pesquisadora, cuja variedade de fala não é a mesma dos sertanejos entrevistados. A formação do aumentativo é feita com os sufixos -ão, -zão e -ona, os quais sofrem harmonização silábica da vogal final com a dissimilação do $o$ em $u$, nas palavras do gênero masculino, ficando as do gênero feminino sem alterações.

Percebemos, como base nos postulados de Lee (1999), que no português brasileiro o sufixo de diminutivo -inho é utilizado nas formas com marcadores de palavra, enquanto o zinho abarca as sem marcadores, as que terminam em sílaba pesada e as proparoxítonas, estas sem ocorrência nos discursos analisados. Os sufixos, além de tamanho expressam afetividade, emoção ou uma conotação pejorativa e ainda relação patronímica. Nos dados observados não percebemos o cunho pejorativo do diminutivo, ao contrário, os usos apontados são expressão de carinho e, de maneira conotativa, o uso patronímico. Em se tratando do aumentativo, este também pode ser usado carinhosa ou pejorativamente.

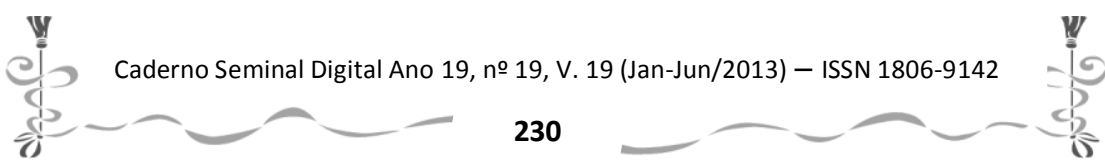


Caderno Seminal Digital

î.

Observamos que a produtividade do aumentativo no falar analisado é reduzida, mas, as ocorrências desta graduação indicam tamanho ou admiração.

O uso da graduação na região de Balsas é muito frequente, principalmente no diminutivo, e expressa, além de tamanho, o sentimento do sujeito falante em relação ao mundo, às coisas e pessoas que o rodeia. Usando o diminutivo, o sertanejo fala de sua vida de maneira expressiva, respeitosa e carinhosa. Expressa simplicidade, modéstia e faz da língua seu objeto de uso diário, modela-a e transforma-a com sua criatividade de sujeito falante.

Consideramos, finalmente, que o emprego do diminutivo é expressivamente maior na fala dos homens em relação às mulheres, o que foi comprovado pelo número de ocorrências levantado (83 para homens e 17 para as mulheres, incluindo a pesquisadora) ${ }^{39}$. Já o aumentativo, mesmo com ocorrência reduzida, é mais utilizado pelas mulheres, uma vez que foi constatada 01 (uma) ocorrência na fala masculina e 03 (três) na feminina. Devemos levar em conta, porém, que a análise foi feita em apenas sete discursos, o que faz com que

${ }^{39}$ Ressaltamos que nossa análise não contemplou o mesmo número de mulheres em relação aos homens. Apesar de ser bem visível na análise a maior ocorrência de diminutivos na fala dos homens, não podemos ser categóricos nessa assertiva por nossa análise ter sido realizada em um número limitado de informantes, principalmente de mulheres.

Caderno Seminal Digital Ano 19, no 19, V. 19 (Jan-Jun/2013) - ISSN 1806-9142

231

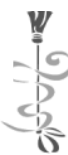


Caderno Seminal Digital

î.

estes resultados não sejam determinantes, senão uma primeira experiência de pesquisa do tema na região eleita.

\section{REFERÊNCIAS}

ALMEIDA, Napoleão M. de. Gramática metódica da língua portuguesa. 39 ed. São Paulo: Saraiva, 1994.

ARAÚJO, Gabriel. Truncamento de reduplicação no português brasileiro. Linguagem: Revista de Estudos da Linguagem. Faculdade de Letras da UFMG. V. 10 - № 1. jan./jul. 2002.

ARAÚJO, G. M. L. de. Análise crítica do conceito de derivação. Linguagem: Revista para estudos de língua e literatura. N. 4/5/6. Ano II e III. Rio de Janeiro: Presença, 1985.

BECHARA, Evanildo. Moderna gramática da língua portuguesa. 37. ed. rev. e ampl. Rio de Janeiro: Lucerna, 2001.

CÂMARA JR., J. M. Estrutura da língua portuguesa. 31. ed. Petrópolis: Vozes, 1970.

BLOOMFIELD, L. Language. Boston: George Aleen \& Unwin, 1979.

CASTRO, M. C. de. Descrição histórica das vogais na fala do sertanejo da região de Balsas-MA. 2008. 184 f. dissertação (Mestrado em Letras e Linguística) - Faculdade de Letras, Universidade Federal de Goiás (UFG), Goiânia.

DELTA. Documentação de Estudos em Linguística Teórica e Aplicada. V. 9. № 1. São Paulo: Educ, 1993.

Caderno Seminal Digital Ano 19, no 19, V. 19 (Jan-Jun/2013) - ISSN 1806-9142
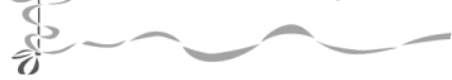

232

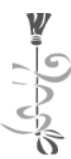


Caderno Seminal Digital

a

DIXON, R. M. W.; AIKHENVALD, A. Y. Word A Cross-

Linguistic Topology. Cambridge: Cambridge University Press, 2007.

HOUAISS, A. Dicionário Houaiss da Língua Portuguesa. Rio de Janeiro: Objetiva, 2001.

LEE, Seung-Hwa. Sobre a formação do diminutivo no português brasileiro. Linguagem: Revista de Estudos da Linguagem. Faculdade de Letras da UFMG. V. 8 - № 1 . jan./jul. 1999.

LYONS, J. Semantics. Cambridge: Cambridge University Press, 1977.

MACAMBIRA, José Rebouças. A estrutura morfo-sintática do português. 9 ed. São Paulo: Pioneira, 1999.

ROSA, Maria Carlota. Introdução à morfologia. 3. ed. São Paulo: Contexto, 2003. 